\title{
Index-Based Inequality in Quality of Care: An Empirical Comparison of Apples and Pears
}

\author{
Vibe Bolvig Hyldgård (DD ${ }^{1,2}$ \\ Søren Paaske Johnsen ${ }^{3}$ \\ Rikke Søgaard (iD ${ }^{1,4}$ \\ 'Department of Public Health, Aarhus \\ University, Aarhus, Denmark; ${ }^{2}$ Health \\ Economics, DEFACTUM, Central Region \\ Denmark, Aarhus, Denmark; ${ }^{3}$ Danish \\ Center for Clinical Health Services \\ Research, Department of Clinical \\ Medicine, Aalborg University, Aalborg, \\ Denmark; ${ }^{4}$ Department of Clinical \\ Research, University of Southern \\ Denmark, Odense, Denmark
}

Purpose: Socioeconomic inequalities have been studied for decades using a variety of methods, but limited attention has been paid to the way methodological differences influence research findings. We aimed to compare index-based measures of socioeconomic inequality in quality of care.

Patients and Data: A national cohort of 110,848 unique stroke patients admitted to publicly funded hospitals in Denmark from 2004-2014 was studied. We used individuallevel data from national registers and the Danish Stroke Registry. Quality of care was defined as fulfilment of process performance measures based on clinical guidelines recommendations (range $0-100 \%$ ). Socioeconomic position was operationalised using information on disposable family income (continuous, DKK) and education (categorical, 7 levels).

Methods: Income- and education-related inequality in quality of care was assessed using concentration indices and the slope index of inequality. All indices were estimated both in absolute and relative terms.

Results: Income-related inequality appeared to be generally higher than education-related inequality. Depending on the choice of index, the inequality in quality of care increased by $5 \%$ or declined by up to $43 \%$ during the study period. Unlike the concentration indices the slope index of inequality was highly sensitive to changes in how the income and educational levels were operationalised.

Conclusion: Careful reporting and interpretation of inequality studies is warranted in order not to misguide decision makers. Unless the policy objective reflects an explicit focus on one specific type of inequality, the use of different inequality indices can lead to different conclusions.

Keywords: slope index of inequality, concentration index, socioeconomic inequality, quality of care

\section{Introduction}

Socioeconomic inequality in health is rising within the OECD countries. ${ }^{1,2}$ Health is a prerequisite for the opportunities we have in life and a rising health inequality thus entails a risk of a vicious circle. ${ }^{3}$ The literature on inequality in health is large whereas far fewer studies focus on inequality related to healthcare delivery. Inequality in healthcare has previously been identified, even in healthcare systems pledging to provide equal care for equal needs, ${ }^{4,5}$ but there is a gap in the literature when it comes to potential inequality in the quality of the delivered care. Hence, the sparse literature mainly deals with healthcare access or healthcare use and not the actual quality of the provided care, which is in contrast to policy attention.

Index-based approaches for assessment of inequality have become popular over recent years. ${ }^{6}$ The basic idea is to quantify the extent to which a policy focus (e.g.
Correspondence: Vibe Bolvig Hyldgård

Tel +4531191504

Fax +45784I 4029

Email vibe.bolvig@ph.au.dk 
quality of care) is distributed across a population according to a rank measure (e.g. income). Resulting in a single estimate that allows for comparison of different policies or time periods ${ }^{4}$ they have appealing properties over classical studies of associations. Further, these indices can be decomposed in terms of what drives the inequality and as such provide highly policy-relevant guidance. ${ }^{7}$

However, the popularity of the index-based methods should not be exercised naively and important points about the crucial match between policy objective and methods used to inform policy must not be overlooked. ${ }^{8}$ Despite the fact that policy is rarely explicit about whether the objective concerns relative or absolute equality, attainment or shortfall in the outcome, or what dimension of socioeconomic position equality is relevant for, research needs to be responsible.

The empirical base of our study is the quality of care for acute stroke patients. Stroke is a leading cause of mortality and morbidity globally, the healthcare costs are staggering and there is a well-developed international professional consensus on the principles of best clinical practice as reflected by detailed clinical guidelines and quality of care performance measures. Among studies of inequality in healthcare much focus has been paid to long-term care, rehabilitation and preventive care while very few focus on acute care. However, studying the quality of acute care may provide an insight into an inequality directly attributable to the healthcare system. In Denmark the quality of acute stroke care has been closely monitored for two decades, however, possible inequality in care has so far not been examined using index-based methods.

The purpose of our study was to compare alternative methods for index-based assessment of socioeconomic inequality in the quality of acute stroke care.

\section{Methods}

\section{Inequality Indices}

Inequality indices can be used to assess the magnitude of inequality across a population. ${ }^{9,10}$ Indices can have either one or two dimensions, i.e. univariate or bivariate. A univariate index gives an estimate of inequality in, for example, life expectancy across a population, whereas a bivariate index measures the inequality over a chosen rank or exposure variable such as income across a population. This way a univariate measure - such as the Gini coefficient - serves as a raw quantification of the inequality focusing solely on the distribution of, for example, healthy life years in a population. ${ }^{11,12}$ Univariate indices are especially useful for comparison across countries where distributions of rank/exposure variables such as income vary due to factors unrelated to a given research question e.g. different tax systems. The significance of exposures - age, ethnicity, occupation etc. - also depends on the setting - location, culture, disease etc. In addition the univariate indices are sometimes more precise as they are based on individual level data whereas rank data are often based on group means. ${ }^{11}$ For policy and intervention purposes we often seek to understand what factors the inequalities are associated with. This is relatively more straightforward when using the bivariate measures but applying decomposition analysis would also allow this with a univariate approach. ${ }^{11}$ The practical impact of presenting one index over another is especially clear when a comparison is made between treatment groups, time periods or other clinically and politically relevant comparators. It has been proposed that a good inequality measure:

1. reflects the socioeconomic dimension to inequalities in health;

2. reflects the experiences of the entire population; and

3. is sensitive to changes in the distribution of the population across socioeconomic groups. (Low and Low, 2004) $)^{13}$

According to Wagstaff et al. (paraphrased by Low and Low) only the concentration indices of inequality (CIIs) and the slope index of inequality (SII) meet these requirements. ${ }^{14}$ These are described in the following sections (for further explanation see Appendix A).

\section{Concentration Indices}

The CIIs stem from the traditional Lorenz curve. ${ }^{15}$ The $y$-axis shows the cumulative share of a given health outcome. The x-axis shows the cumulative proportion of individuals ranked from most to least disadvantaged in terms of the given health outcome for univariate concentration curves (Lorenz curves) and the socioeconomic situation for bivariate concentration curves. A CII is calculated as twice the area between the diagonal line (representing equality) and a graph of $\mathrm{f}(\mathrm{x})$. Figure 1 illustrates a bivariate CII. This area will be small unless the inequality is very high so an alternative graphical presentation is to let the y-axis give the distance between the curve and the equality line (see e.g. Søgaard and Lindholt $2019^{4}$ ). 


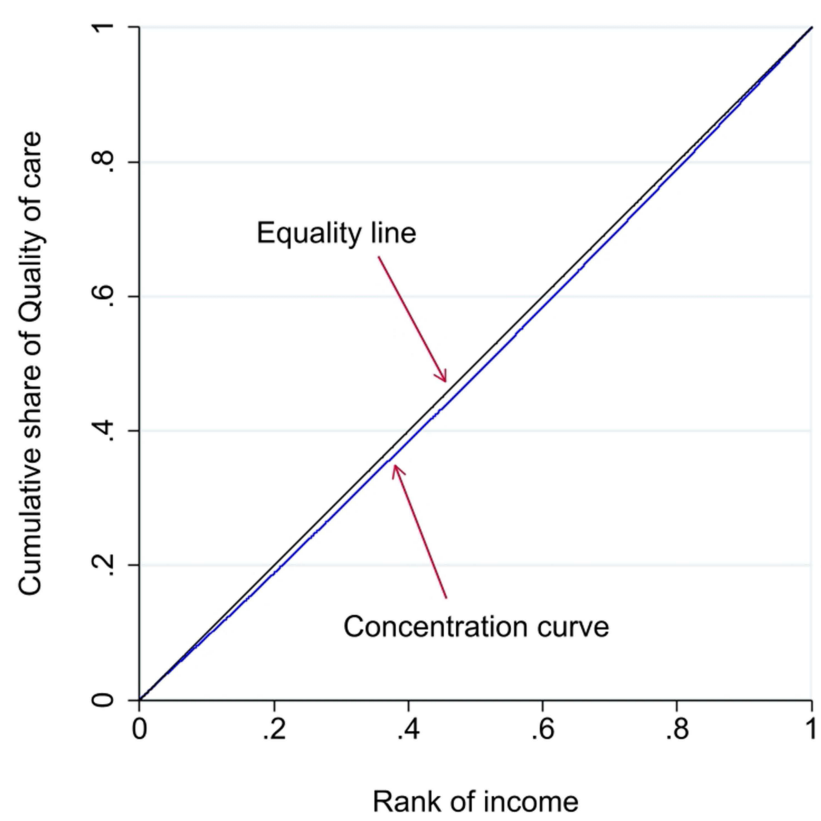

Figure I Graphical illustration of the income-related inequality in quality of care using absolute concentration index (2004-14).

The range of the CIIs is $[0 ; 1]$ for the univariate and $[-1 ; 1]$ for the bivariate versions. An index of 0 signifies total equality and the further from 0 the $\mathrm{CII}$ is, the more unequal is the distribution. A positive CII means that the privileged experience higher quality of care than the unprivileged. Inversely a negative CII means that the unprivileged experience higher quality of care than the privileged.

\section{Slope and Relative Index of Inequality}

The SII is an absolute measure of the difference in a regression-based health outcome estimate between the most and the least socioeconomically privileged individual in the population, i.e. the health gap in the population. The relative index of inequality (RII) measures the ratio between these extremes - parallel to an odds ratio between the worst off and the best off group or individual ${ }^{16}$ - and is equivalent to a relative CII. ${ }^{14,17}$ Both the SII and the RII are regression-based, hence there are no univariate versions. The indices can assume all values depending on the difference between the most and the least privileged individual in the study population and is closely dependent on the definition of both the health outcome and the exposure/ rank variable. This means that neither the size of the index nor the operational sign - whether positive or negative can be interpreted out of context. In addition the SII is dependent on the number of categories in a given rank $-\mathrm{i}$. e. the unit of analysis ${ }^{18}-$ due to the way it is constructed.
If an outcome is completely equally distributed the SII equals 0 and the RII equals 1 and the further the index is from 0 and 1 , respectively, the more inequality there is (see Figure 2 for illustration).

\section{Data}

We applied patient-level data from the Danish Stroke Register (DSR), a validated, nationwide, clinical quality database. ${ }^{19}$ It is mandatory for all Danish hospital departments treating acute stroke patients to report to the DSR. The data represent consecutive unique patients from 20032013. These data were linked with national registers on education and income under Statistics Denmark using personal identification numbers.

\section{Study Population and Setting}

Stroke is used as the empirical case in this study. There is a long tradition for monitoring the early and medium-term care of all acute stroke patients in Denmark and the registration practice includes an indication of each patient's specific medical needs. We included all adults $\left(18^{+}\right.$ years) who were hospitalised with an acute stroke. Patients registered with an ischemic stroke or intracerebral hemorrhage were included, whereas patients with transient ischemic attack were excluded. We only included the first event for patients with multiple recorded events during the study period. Acute stroke care is exclusively provided at publicly funded hospitals in Denmark.

\section{Socioeconomic Characteristics}

Each patient's socioeconomic characteristics, i.e. the exposure/rank variables, were operationalised as disposable family income and the patient's highest achieved educational level in seven levels from shortest (primary school) to longest (doctoral or equivalent). These data were obtained for the year prior to the stroke from Statistics Denmark. ${ }^{20}$ Patients were excluded if their exposure/rank data were missing.

\section{Quality of Care}

Quality of care was operationalised as a composite measure based on 16 process performance measures of equal weight. These measures are based on recommendations from the national clinical guidelines for acute stroke, including admission to a specialised stroke unit, early brain imaging, antiplatelet therapy, and early assessment by a physiotherapist and an occupational therapist (see Appendix B for the full set of performance measures ${ }^{5}$ ). Specifically we used the percentage of medically relevant 


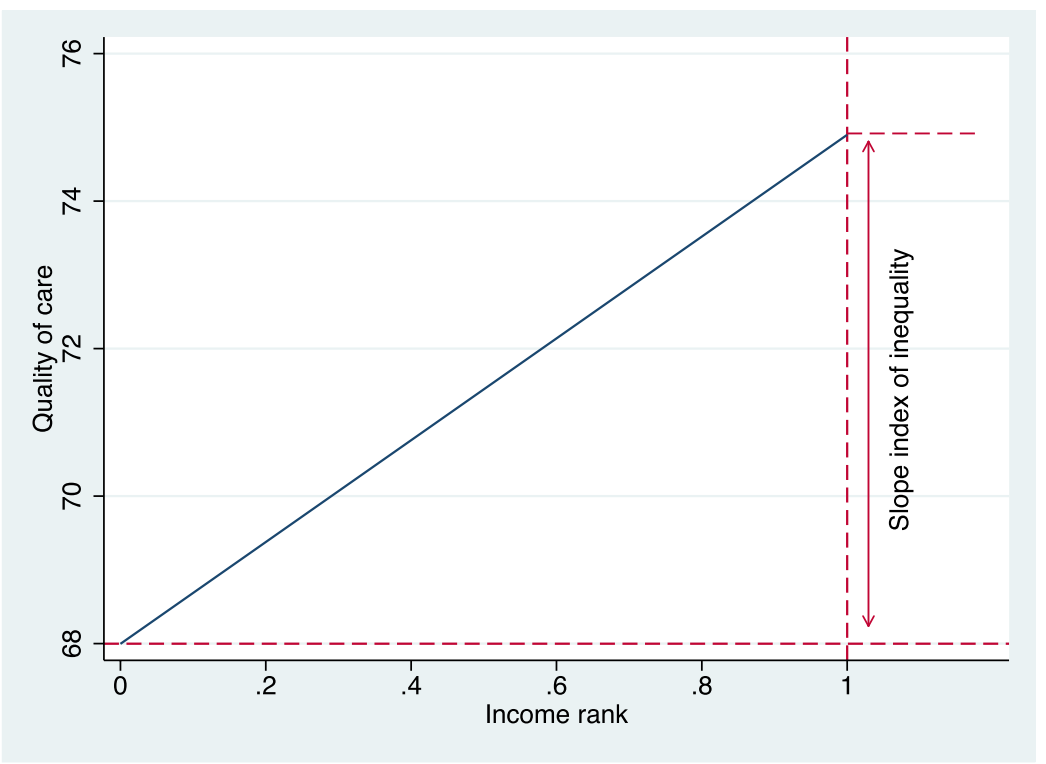

Figure 2 Graphical illustration of the income-related inequality in quality of care using slope index of inequality (2004-14).

care achieved (or not achieved) by each individual patient. During admission the patients were classified as eligible or not for each performance measure according to the presence of contraindications, e.g. a patient considered moribund at the time of admission would not be considered eligible for an assessment by an occupational therapist. $^{21,22}$ The medical relevance of each performance measure is therefore incorporated into the registration and consequently included in this study.

\section{Analysis}

We estimated an absolute, a relative attainment and a relative shortfall $\mathrm{CII}^{23}$ In addition to bivariate indices we calculated the univariate indices to illustrate the unadjusted distribution of quality of care. We used the good practice method suggested by Erreygers and Van Ourti for the bivariate CIIs. ${ }^{24}$ This approach requires a classification of the nature of the chosen outcome. We study quality of care as bounded between 0 and $100 \%$ and assign equal weight to each quality criterion. This classifies the outcome as ratioscaled, rendering the modified CII appropriate. ${ }^{24}$ We estimated two RIIs for each rank to illustrate the consequence of defining the outcome in terms of either what is achieved (which in the health economic tradition is called attainment) or what is not achieved (called shortfall ${ }^{8}$ or adverse event ${ }^{25}$ by health economists and epidemiologists, respectively).

Calendar time was used to define the comparators in this study. According to the year patients were discharged the study period was split into two: 2004-2008 and 2009-
2014. We estimated each of the indices in the two periods and estimated the change in inequality both in absolute and relative terms between the two periods to assess the development in inequality over time. Z-tests were used to test null hypotheses of no change over time. We altered the definitions of the rank/exposure variable to test the robustness of the results. All analyses were performed in STATA 16 , where the epidemiologic indices were estimated using RIIGEN $^{26,27}$ - applying Poisson and linear regressions to derive the RIIs and SIIs, respectively. The health economic indices were all estimated using conindex. ${ }^{28}$

\section{Research Ethics}

According to Danish law informed patient consent was not required, as the study did not involve patient contact. The project was approved by the Data Protection Agency. Data were handled in accordance with the Person Data act.

\section{Results}

Table 1 gives an overview of the study population characteristics with regards to the quality of care, income and education and how these changed over time. A total of 110,848 unique patients were included. In general, the quality of care increased over time with 8 percentage points and the interquartile range shifted upwards and narrowed. Income and education data was missing for 9 and $12 \%$ of the patients, respectively. Income and educational level increased slightly over time. 
Table I Study Population

\begin{tabular}{|c|c|c|c|c|c|c|c|c|}
\hline & \multirow[t]{2}{*}{$\mathbf{N}$} & \multirow[t]{2}{*}{ Mean } & \multicolumn{3}{|c|}{ Range } & & & \\
\hline & & & $25 \%$ & $50 \%$ & $75 \%$ & & & \\
\hline $\begin{array}{l}\text { Quality of } \\
\text { care }\end{array}$ & 110,848 & 70.40 & 57.14 & 75.00 & 90.00 & & & \\
\hline 2004-2008 & 52,767 & 66.24 & 50.00 & 71.43 & 85.71 & & & \\
\hline $2009-2014$ & 58,081 & 74.18 & 66.67 & 76.92 & 90.00 & & & \\
\hline $\begin{array}{l}\text { Family } \\
\text { income (in } \\
\text { thousands) }\end{array}$ & 100,722 & 270.91 & 156.25 & 212.34 & 319.02 & & & \\
\hline 2004-2008 & 47,762 & 257.42 & 150.16 & 202.67 & 302.15 & & & \\
\hline $2009-2014$ & 52,960 & 283.08 & 162.00 & 222.86 & 334.91 & & & \\
\hline & & & & & n (\%) & & & \\
\hline & $\mathbf{N}$ & Primary & $\begin{array}{l}\text { Lower } \\
\text { Secondary }\end{array}$ & $\begin{array}{c}\text { Upper } \\
\text { Secondary }\end{array}$ & $\begin{array}{c}\text { Short } \\
\text { Tertiary }\end{array}$ & $\begin{array}{l}\text { Bachelor or } \\
\text { Equivalent }\end{array}$ & $\begin{array}{l}\text { Master or } \\
\text { Equivalent }\end{array}$ & $\begin{array}{c}\text { Doctorial or } \\
\text { Equivalent }\end{array}$ \\
\hline $\begin{array}{l}\text { Educational } \\
\text { level }\end{array}$ & 97,512 & $149(0.15)$ & $47,102(48.30)$ & $35,716(36.63)$ & $2|4|(2.20)$ & 8966 (9.19) & 3353 (3.44) & $85(0.09)$ \\
\hline 2004-2008 & $43,84 I$ & $66(0.15)$ & $22,314(50.90)$ & $15,556(35.48)$ & $887(2.02)$ & $3642(8.3 \mathrm{I})$ & I353 (3.09) & $23(0.05)$ \\
\hline $2009-2014$ & 53,671 & $83(0.15)$ & 24,788 (46.19) & $20,160(37.56)$ & 1254 (2.34) & 5324 (9.92) & $2000(3.73)$ & $62(0.12)$ \\
\hline
\end{tabular}

The univariate indices in Table 2 establish how (un) equally the quality of care is distributed in the study population. When we recall that a CII of zero signifies equality we can see that inequality was present. This inequality was most evident in the attainment relative $\mathrm{CII}$ - in other words high quality care was more unequally distributed than poor quality care in relative terms. The inequality was smallest in absolute terms.

Table 2 also shows a decrease in inequality over time. This decrease was larger in the absolute and the relative attainment indices than in the shortfall relative index, which means that the inequality in poor quality of care dropped less over time than the inequality in high quality care. However, the inequality in poor quality care was lower at baseline and thus the potential for a decrease in absolute numbers was lower.

Table 3 presents the bivariate indices. All the concentration indices revealed an income-related inequality in quality of care, which favored the most privileged patients. The inequality decreased over time, varying from a relative fall between $17 \%$ and $43 \%$. The education related inequality was smaller and there were no statistically significant changes over time.

The SII show that the income-related inequality decreased in absolute terms. The most privileged patient was predicted to attain 9.1 percentage points higher quality of care compared with the least privileged in the first period. This difference dropped to 5.7 in the second

Table 2 Univariate Indices of Inequality in Quality of Care

\begin{tabular}{|l|r|r|r|r|r|}
\hline & \multicolumn{1}{|c|}{ 2004-08 } & 2009-14 & Absolute Difference & 95\% Cl & $\begin{array}{c}\text { Relative } \\
\text { Difference }\end{array}$ \\
\hline N & 52,767 & 58,081 & & \\
ACII & 0.648 & 0.462 & -0.187 & $(-0.188 ;-0.185)$ & $-29 \%$ \\
ARCII & 0.245 & 0.156 & -0.089 & $(-0.090 ;-0.088)$ & $-36 \%$ \\
SRCI* & 0.480 & 0.447 & -0.033 & $(-0.035 ;-0.031)$ & $-7 \%$ \\
\hline
\end{tabular}

Note: *Negative operational signs are ignored.

Abbreviations: $\mathrm{Cl}$, confidence interval; $\mathrm{ACll}$, absolute concentration index; ARCIl, attainment relative concentration index; SRCII, shortfall relative concentration index. 
Table 3 Bivariate Indices of Inequality in Quality of Care

\begin{tabular}{|c|c|c|c|c|c|c|}
\hline & & 2004-08 & 2009-14 & $\begin{array}{l}\text { Absolute } \\
\text { Difference }\end{array}$ & $95 \% \mathrm{Cl}$ & $\begin{array}{c}\text { Relative } \\
\text { Difference }\end{array}$ \\
\hline \multicolumn{7}{|l|}{ Income related } \\
\hline & $N$ & 47,762 & 52,960 & & & \\
\hline & ACII & 0.068 & 0.043 & -0.025 & $(-0.032 ;-0.017)$ & $-36 \%$ \\
\hline & ARCII & 0.025 & 0.015 & -0.011 & $(-0.014 ;-0.008)$ & $-43 \%$ \\
\hline & SRCII* & 0.050 & 0.042 & -0.009 & $(-0.014 ;-0.003)$ & $-17 \%$ \\
\hline & SII & 8.279 & 5.214 & -3.065 & $(-4.650 ;-1.479)$ & $-37 \%$ \\
\hline & ARII & 1.165 & 1.091 & -0.074 & & $-6 \%$ \\
\hline & SRII* & 0.740 & 0.779 & 0.039 & & $5 \%$ \\
\hline \multicolumn{7}{|c|}{ Education related } \\
\hline & $\mathrm{N}$ & $43,84 I$ & 53,671 & & & \\
\hline & ACII & 0.024 & 0.022 & -0.001 & $(-0.008 ; 0.006)$ & $-5 \%$ \\
\hline & ARCII & 0.009 & 0.008 & -0.001 & $(-0.037 ; 0.001)$ & $-14 \%$ \\
\hline & SRCII* & 0.018 & 0.022 & 0.004 & $(-0.009 ; 0.002)$ & $21 \%$ \\
\hline & SII & 1.334 & 4.803 & 3.469 & $(-1.701 ; 8.639)$ & $260 \%$ \\
\hline & ARII & 1.066 & 1.055 & -0.011 & & $-1 \%$ \\
\hline & SRII* & 0.876 & 0.856 & -0.020 & & $-2 \%$ \\
\hline
\end{tabular}

Note: *Negative operational signs are ignored.

Abbreviations: $\mathrm{Cl}$, confidence interval; $\mathrm{ACll}$, absolute concentration index; ARCll, attainment relative concentration index; SRCll, shortfall relative concentration index; SII, slope index of inequality (rank income/I00); ARII, attainment relative index of inequality; SRII, shortfall relative index of inequality.

period. Thus, the difference in absolute income inequality in quality of care was lowered 3.4 percentage points corresponding to a $37 \%$ fall.

The RIIs show that the most privileged patient experienced a 1.2 times higher level of attained quality of care than the least privileged patient in the first period which fell to 1.1 in the second period. At the same time the least privileged patient experienced a 1.3 times higher level of unattained quality of care than the most privileged patient falling to 1.2 in the second period. Hence, the relative inequalities in attained and non-attained quality of care were both lowered despite opposite operational signs (as equality exists when $\mathrm{RII}=1$ ). As with the CIIs the education related inequalities are smaller and the changes over time are statistically insignificant. Especially the SII is ambiguous with an absolute change over time of 3.5 (95\% CI: $-1.7 ; 8.6)$ which yields a point-estimate of the relative difference over time of $260 \%$.
We found that the indices in general were robust to changes in the definition of rank/exposure variable (income and education) and the consequent change in the unit of analysis except for the SII. Table 4 illustrates how volatile the SII is when the definition of the income is changed from a practically individual level (the raw income and the log(income)) to group level (in categories of $100^{\text {ths }}$ or $1000^{\text {ths }}$ ). Education could only be ranked in three to seven categories, which made no difference to the results.

In continuation hereof the SII is also more sensitive to handling of missing data. Approximately $10 \%$ of the study population had missing income data (see Table 1) and the handling of this affected the SII $(7.6(95 \% \mathrm{CI}$ : 6.6; 8.6) with missingness indicator and 6.9 (95\% CI: $6.0 ; 7.8)$ with complete data only).

The SIIs in Figure 3 illustrate that the quality of care improved from the first to the second period and shows

Table 4 SII Under Different Definitions of Income

\begin{tabular}{|l|r|r|r|r|r|r|}
\hline & Observations in Model (n) & 2004-08 & 2009-14 & Absolute Difference & 95\% Cl & Relative Difference \\
\hline Raw income & 99,662 & 10.087 & 6.539 & -3.548 & $(-4.620 ;-2.477)$ & $-35 \%$ \\
Log(income) & 98,263 & 10.157 & 6.528 & -3.629 & $(-4.702 ;-2.555)$ & $-36 \%$ \\
Income/100 & 14,165 & 8.279 & 5.214 & -3.065 & $(-4.650 ;-1.479)$ & $-37 \%$ \\
Income/1000 & 2696 & 5.260 & 4.822 & -0.438 & $(-3.44 I ; 2.566)$ & $-8 \%$ \\
\hline
\end{tabular}



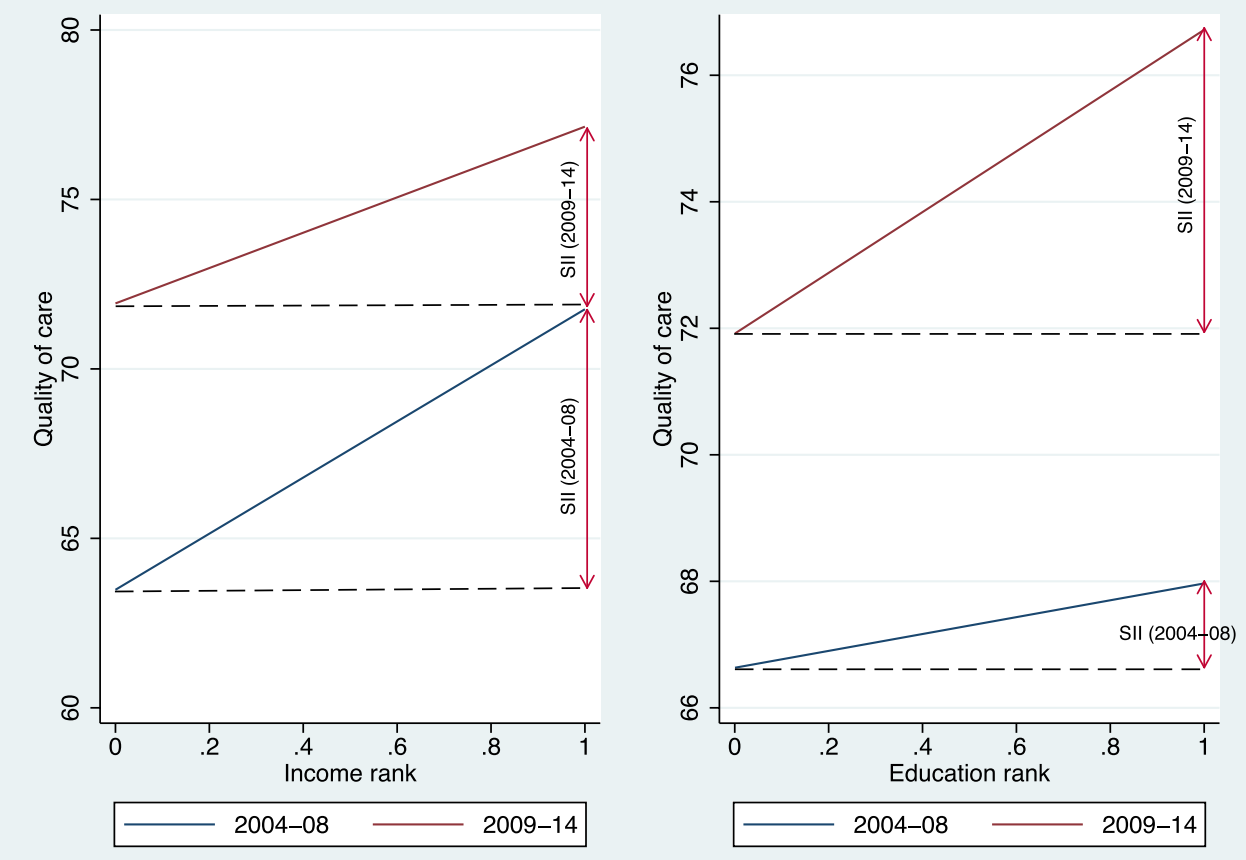

Figure 3 Slope inequality indices over time.

how this improvement was distributed across patient income and education, respectively. The income-related inequality dropped - in absolute and relative terms while the education-related inequality seemed to have increased. However, as shown in Table 3, the assessment of the inequality change related to education was rather imprecise (SII 3.47, 95\% CI: -1.70 ; 8.64).

\section{Discussion}

This study demonstrates that the extent of socioeconomic inequality in quality of healthcare depends on the method used to assess it. This is in itself not surprising but it is an often-neglected point that the methods actually represent different definitions of inequality. The problem arises if the methods are used interchangeably and thus end up misguiding policy-making. Our study is an illustration of the consequences of the choice of inequality index, which is intended to increase awareness. For the case of stroke, the past years' focus on clinical quality have increased inequality by $5 \%$ based on one measure (SRII) and reduced inequality by $43 \%$ according to another measure (ARCII). These large differences between relative and absolute measures arise in comparisons of groups or, in this case, over time. This is in line with the recommendations of the STROBE and CONSORT statements on effect studies, and with Søgaard and Lindholt on inequality indices, that both relative and absolute measures should be reported. ${ }^{4,29-32}$ In King, Harper and Young's review of health inequality studies, only $2 \%$ of the studies reported both measures. ${ }^{32}$

Depending on the setting other comparators could be relevant to study, e.g. gender or race. ${ }^{33,34}$ In the given setting, time was a relevant choice of comparator as it has been found that a positive development in quality of care occurred over time. ${ }^{5}$ This study shows that the income-related inequality in quality of care, as an additional policy focus, appears to have decreased over time (with the exception of the results based on the shortfall relative index). This is a remarkable finding in that lifting the population mean often has negative distributional consequences in that the higher socioeconomically ranked individuals benefit more from better quality than the socioeconomically worse off. ${ }^{10,35}$ The socioeconomic structure of the study population changed slightly over the studied period. This shift might partly explain the somewhat paradoxical finding of the education-related SII changes. In cases where sizable shifts occur in the distribution of a given exposure the results of a SII can be misleading. ${ }^{36}$ Renard et al. calls attention to this risk and recommends complementing RIIs and SIIs with assessments of any 
changes in the distribution of income, education etc. using population attributable fractions and socioeconomic group shares. ${ }^{36}$ This risk of misinterpretation in the interpretation of SIIs supports the need for informed and transparent communication of inequality indices and perhaps calls for a presentation of multiple indices. Unlike the SIIs the CIIs are robust to changes in the exposure/rank making them a good supplement - if not alternative - to the SIIs in such cases.

The technical properties of the different indices should be studied further. In addition to influencing the assessment and presentation of inequality, we also illustrate how the diverse indices yield different estimation precision and sensitivity to rank definition. Specifically the SII was found to be sensitive to changes in the unit of analysis $i$. e. how we operationalised the socioeconomic ranking. Asada describes this issue in relation to studying groups or individuals. When working with groups only the mean value of the group is incorporated in the model while intragroup differences are overlooked. ${ }^{18}$ For more in-depth descriptions of the methodological approaches we suggest Mackenbach et al., ${ }^{35}$ Moreno-Betancur et al., ${ }^{37}$ Erreygers and Van Ourti ${ }^{24}$ and Asada et al. ${ }^{38}$

The graphic presentation of inequality indices also set the indices apart. The CII graphs can be directly compared across studies. They fall within the same scale and are defined as twice the area between the diagonal and the graph. However, in many instances - our study included the area is so narrow that it is difficult to comprehend. The SII, the distance from minimum to maximum, can be more intuitive, however, unlike the CIIs it requires knowledge of the context and the scale of the outcome.

The empirical data and case represent a clear strength in this study. Quality of care was based on a detailed assessment of the clinical needs of the individual patient made by the health professionals providing care for the patient. The thorough monitoring of their individual treatment, and especially of their individual treatment needs makes the case highly suitable for the study of inequality in quality of care. This comprehension reflects the present setting in which a stated health policy goal is to provide equal quality of care for equal needs. However, the unique case and setting can also represent a limitation, as the generalizability of the empirical findings may be narrow. In this study patients' needs were incorporated in the outcome but covariate adjustment is possible when working with indices. ${ }^{37}$ This would have allowed for comparison across studies with patient groups of varying age, comorbidity etc. As the outcome measure in our study already accounted for patient characteristics and individual healthcare needs we did not make such adjustment. Besides, the focus of the present study was to compare the methods of the health economic and epidemiologic disciplines and it was a priority not to add further complexity to the empirical analyses.

A recurring limitation when studying social or socioeconomic inequality is the operationalisation of socioeconomic position. In this study we focused on disposable family income, as an unbounded measure with large variation, versus educational level as a bounded measure with a much smaller range and resulting in equal rank for a large number of individuals that might not have equal social or socioeconomic position in society. According to recent literature, a continuous rank measure is preferable. ${ }^{6}$ Further, the age of the population raises questions about alternative measures such as household wealth. ${ }^{39}$

An important policy aspect of this and the other studies in this field lies in the value judgements potentially embedded in the different methodologies. ${ }^{17}$ The political and clinical setting is obviously important in policy decision-making but also in the process of research. Increasing the transparency and recognising the normative judgements in research will aid a better match between policy goals and empirical studies and hopefully lead to (appropriately) informed decisions. According to Low and Low we must be able to measure inequality if we are to set equality goals, and the choice of measure depends completely on these policy goals. ${ }^{13}$ The CII for instance could imply a normative conception as a health distribution that favors the already socioeconomically favored individuals bears a negative sign $(\mathrm{CII}<0)$ and a positive sign when the socioeconomically disadvantaged are favored $(\mathrm{CII}>0) .{ }^{17}$ There may also be policy incentives to present only shortfall or attainment relative estimates depending on e.g. political aims. When adverse events are rare, as in the present study, any potential gain/improvement will naturally be small (law of diminishing marginal returns) making an attainment relative index more appealing to some.

Taking a normative stance should not fall upon the researchers, we should simply be transparent about the potentially embedded value judgements in the methods used. $^{40}$

\section{Conclusion}

We compared alternative index-based methods in the assessment of socioeconomic inequality in the quality of 
care for acute stroke patients. With this study we underline the need for conscientious reporting and interpretation of inequality studies. This need becomes especially clear in the light of decision makers relying on research to guide health policy efforts.

\section{Abbreviations}

ACII, absolute concentration index; ARCII, attainment relative concentration index; $\mathrm{CII}$, concentration index of inequality; CI, confidence interval; DSR, Danish Stroke Register; RII, relative index of inequality; SRCII, shortfall relative concentration index; SII, slope index of inequality.

\section{Acknowledgments}

The authors have no acknowledgements to make.

\section{Funding}

No funding was received for this this study.

\section{Disclosure}

The authors have no conflicts of interest for this work.

\section{References}

1. Marmot M. Health equity in England: the Marmot review 10 years on. $B M J$. 2020;368. doi:10.1136/bmj.m693

2. Bor J, Cohen GH, Galea S. Population health in an era of rising income inequality: USA, 1980-2015. Lancet. 2017;389 (10077):1475-1490. doi:10.1016/S0140-6736(17)30571-8

3. Organization for Economic Co-operation and Development. Health for Everyone?: Social Inequalities in Health and Health Systems. Paris; 2019. doi:10.1097/00000446-194504000-00011

4. Søgaard R, Lindholt JS. Assessment of inequality alongside policy-oriented trials: an empirical framework based on the case of screening. Epidemiology. 2019;30(5):706-712. doi:10.1097/ EDE.0000000000001040

5. Hyldgård VB, Johnsen SP, Støvring H, Søgaard R. Socioeconomic status and acute stroke care: has the inequality gap been closed? Clin Epidemiol. 2019;11:933-941. doi:10.2147/CLEP.S218322

6. Pulok MH, van Gool K, Hajizadeh M, Allin S, Hall J. Measuring horizontal inequity in healthcare utilisation: a review of methodological developments and debates. Eur $J$ Heal Econ. 2020;21 (2):171-180. doi:10.1007/s10198-019-01118-2

7. Heckley G, Gerdtham UG, Kjellsson G. A general method for decomposing the causes of socioeconomic inequality in health $J$ Health Econ. 2016;48:89-106. doi:10.1016/j.jhealeco.2016.03.006

8. Kjellsson G, Gerdtham U, Petrie D. Lies, damned lies, and health inequality measurements. Epidemiology. 2015;26(5):673-680. doi:10.1097/EDE.0000000000000319

9. Jacquet E, Robert S, Chauvin P, Menvielle G, Melchior M, Ibanez G. Social inequalities in health and mental health in France. The results of a 2010 population- based survey in Paris metropolitan area. PLoS One. 2018;13(9):e0203676. doi:10.5061/dryad.tg34gv7.Funding

10. Marmot MG, Allen J, Goldblatt P, et al. Fair society, healthy lives: the Marmot ReviewSource: SCIE Social Care Online-01 January 2010. London: Marmot Review; 2010. doi:10.1016/j. puhe.2012.05.014.
11. Asada Y. A summary measure of health inequalities. In: Eyal N, Hurst SA, Norheim OF, Wikler D, editors. Inequalities in Health: Concepts, Measures, and Ethics. 1st ed. Oxford: Oxford University Press; 2013. doi:10.1093/acprof

12. Regidor E. Measures of health inequalities: part 2. J Epidemiol Community Heal. 2004;58:900-903. doi:10.1136/jech.2004.023036

13. Low A, Low A. Measuring the gap: quantifying and comparing local health inequalities. $J$ Public Health. 2004;26(4):388-395. doi:10.1093/pubmed/fdh175

14. Wagstaff A, Paci P, Van DE. On the measurement of inequalities in health. Soc Sci Med. 1991;33(5):545-557. doi:10.1016/02779536(91)90212-U

15. Regidor E. Measures of health inequalities: part 1. J Epidemiol Community Heal. 2004;58:858-861. doi:10.1136/jech.2003. 015347

16. Dalstra JAA, Kunst AE, Geurts JJM, Frenken FJM, Mackenbach JP. Trends in socioeconomic health inequalities in the Netherlands, 1981-1999. J Epidemiol Community Health. 2002;56(12):927-934. doi:10.1136/jech.56.12.927

17. Harper SAM, King NB, Stephen C, Reichman ME, Western C, Cancer N. Implicit value judgments in the measurement of health inequalities. Milbank Q. 2010;88(1):4-29. doi:10.1111/j.14680009.2010.00587.x

18. Asada Y. A framework for measuring health inequity. $J$ Epidemiol Community Health. 2005;59(8):700-705. doi:10.1136/ jech.2004.031054

19. Wildenschild C, Mehnert F, Wernich Thomsen R, et al. Registration of acute stroke: validity in the Danish stroke registry and the Danish national registry of patients. Clin Epidemiol. 2013;6:27-36. doi:10.2147/CLEP.S50449

20. Petersson F, Baadsgaard M, Thygesen LC. Danish registers on personal labour market affiliation. Scand J Public Health. 2011;39(7 Suppl):95-98. doi:10.1177/1403494811408483

21. Palnum KD, Andersen G, Ingeman A, Krog BR, Bartels $P$, Johnsen SP. Sex-related differences in quality of care and short-term mortality among patients with acute stroke in Denmark: a nationwide follow-up study. Stroke. 2009;40(4):1134-1139. doi:10.1161/STROKEAHA.108.543819

22. Johnsen SP, Ingeman A, Hundborg HH, Schaarup SZ, Gyllenborg J. The Danish stroke registry. Clin Epidemiol. 2016;8:697-702. doi:10.2147/CLEP.S10366

23. Carrieri V, Jones AM. Inequality of opportunity in health: a decomposition-based approach. Health Econ. 2018;27 (12):1981-1995. doi:10.1002/hec.3814

24. Erreygers G, Van Ourti T. Measuring socioeconomic inequality in health, health care and health financing by means of rank-dependent indices: a recipe for good practice. J Health Econ. 2011;30 (4):685-694. doi:10.1016/j.jhealeco.2011.04.004

25. Keppel K, Pamuk E, Lynch J, et al. Methodological issues in measuring health disparities. Vital Heal Stat Ser 2 Data Eval Methods Res. 2005;141:1-16.

26. Kroll LE. RIIGEN: stata module to generate variables to compute the economics, relative index of inequality. 2013.

27. Mackenbach JP, Kunst AE. Measuring the magnitude of socio-economic inequalities in health: an overview of available measures illustrated with two examples from Europe. Soc Sci Med. 1997;44(6):757-771. doi:10.1016/S0277-9536(96)00073-1

28. O'Donnell O, O'Neill S, Van Ourti T, Walsh B. conindex: estimation of concentration indices. Stata J. 2016;16(1):112-138. doi:10.1177/ $1536867 \times 1601600112$

29. von Elm E, Altman DG, Egger M, Pocock SJ, Gøtzsche PC, Vandenbroucke JP. The strengthening the reporting of observational studies in epidemiology (STROBE) statement: guidelines for reporting observational studies. Lancet. 2007;370:1453-1457. doi:10.1016/ S0140-6736(07)61602-X 
30. Cobos-Carbó A, Augustovski F. CONSORT 2010 declaration: updated guideline for reporting parallel group randomised trials. Med Clin. 2011;137(5):213-215. doi:10.1016/j.medcli.2010.09.034

31. Asada Y. On the choice of absolute or relative inequality measures. Milbank $\quad$ Q. 2010;88(4):616-622. doi:10.1111/j.14680009.2010.00614.x

32. King NB, Harper S, Young ME. Use of relative and absolute effect measures in reporting health inequalities: structured review. $B M J$. 2012;345. doi:10.1136/bmj.e5774

33. Arrich J, Müllner M, Lalouschek W, Greisenegger S, Crevenna R, Herkner H. Influence of socioeconomic status and gender on stroke treatment and diagnostics. Stroke. 2008;39:2066-2072. doi:10.1161/ STROKEAHA.107.506147

34. Kimball MM, Neal D, Waters MF, Hoh BL. Race and income disparity in ischemic stroke care: nationwide inpatient sample database, 2002 to 2008. J Stroke Cerebrovasc Dis. 2014;23(1):17-24. doi:10.1016/j.jstrokecerebrovasdis.2012.06.004

35. Mackenbach JP, Stirbu I, Roskam AJR, et al. Socioeconomic inequalities in health in 22 European countries. $N$ Engl J Med. 2008;358:2468-2481. doi:10.1056/NEJMsa0707519
36. Renard F, Devleesschauwer B, Speybroeck N, Deboosere P. Monitoring health inequalities when the socio-economic composition changes: are the slope and relative indices of inequality appropriate? Results of a simulation study. BMC Public Health. 2019;19(1):1-9. doi:10.1186/s12889-019-6980-1

37. Moreno-betancur M, Latouche A, Menvielle G, et al. Relative index of inequality and slope index of inequality a structured regression framework for estimation. Epidemiology. 2015;26(12):518-527. doi:10.1097/EDE.0000000000000311

38. Asada Y, Hurley J, Norheim OF, Johri M. A three-stage approach to measuring health inequalities and inequities. Int $J$ Equity Health. 2014;13:1-13. doi:10.1186/s12939-014-0098-y

39. Galobardes B, Shaw M, Lawlor DA, Lynch JW, Smith GD. Indicators of socioeconomic position (part 1). J Epidemiol Community Health. 2006;60(1):7-12. doi:10.1136/jech.2004.023531

40. Wagstaff A. Commentary: value judgments in health inequality measurement. Epidemiology. 2015;26(5):670-672. doi:10.1097/ EDE.0000000000000357
Clinical Epidemiology

\section{Publish your work in this journal}

Clinical Epidemiology is an international, peer-reviewed, open access, online journal focusing on disease and drug epidemiology, identification of risk factors and screening procedures to develop optimal preventative initiatives and programs. Specific topics include: diagnosis, prognosis, treatment, screening, prevention, risk factor modification, systematic reviews, risk \& safety of medical interventions, epidemiology \& biostatistical methods, and evaluation of guidelines, translational medicine, health policies \& economic evaluations. The manuscript management system is completely online and includes a very quick and fair peer-review system, which is all easy to use. 